\title{
Multi-Community Cardiopulmonary Resuscitation Education by Medical Students
}

\author{
Kenton L. Anderson ${ }^{1}$, Kian Niknam ${ }^{1}$, Larry Laufman ${ }^{2}$, Stefanie S. Sebok-Syer ${ }^{3}$, Sara Andrabi ${ }^{4}$ \\ 1. Emergency Medicine, Stanford University School of Medicine, Palo Alto, USA 2. Medicine, Baylor College of \\ Medicine, Houston, USA 3. Emergency Medicine, Stanford University, Palo Alto, USA 4. Emergency Medicine, Baylor \\ College of Medicine, Houston, USA
}

Corresponding author: Kenton L. Anderson, kentona@stanford.edu

\begin{abstract}
Introduction

One purpose of the hands-only cardiopulmonary resuscitation (HOCPR) program is to simplify CPR instruction to encourage more bystanders to take action during cardiac arrest. Although the program has been successfully implemented in traditional classroom settings, the utility of large-scale training events has not been well-explored. We hypothesized that CPR knowledge and comfort levels would increase through a large-scale, multi-community HOCPR training event. We also explored what effect this training event had on perceived barriers to bystander-performed CPR.
\end{abstract}

Methods

A convenience sample participated in HOCPR training on a single day across 10 Texas cities. A sub-sample completed training questionnaires, including a five-item CPR pre- and post-test. A follow-up questionnaire was conducted two years after the event. The primary outcome of interest was the difference in cardiopulmonary resuscitation (CPR) knowledge and comfort level between pre- and post-event questionnaires. Demographic contributions were also assessed.

Results

A total of 4,253 participants were trained, 1,416 were enrolled upon submitting matching pre- and postevent questionnaires, and 101 (14\%) submitted follow-up questionnaires. Mean knowledge scores increased from pre-training $(2.7 \pm 1.6$ standard deviation $(\mathrm{SD}))$ to post-training $(4.7 \pm 0.76 \mathrm{SD})(\mathrm{p}<0.001)$. Follow-up test scores $(3.8 \pm 1.1 \mathrm{SD})$ remained higher than pre-test scores $(\mathrm{p}<0.001)$. Comfort with HOCPR increased from 59\% (95\% confidence interval (CI) 56 - 61) to 96\% (95\% CI 95 - 97). Pre- and post-knowledge scores differed significantly by education level $(\mathrm{p}<0.001)$, ethnicity $(\mathrm{p}<0.001)$, and income $(\mathrm{p}<0.001)$. Education contributed significantly to comfort at both pre- $(\mathrm{p}=0.015)$ and post-training $(\mathrm{p}=0.026)$, but ethnicity and income did not. Before training, the most common barrier to performing CPR was lack of knowledge 59\% (95\% CI 55 - 62); after training, the most common barrier was fear of causing harm 34\% (95\% CI 29 - 40).

Received 04/22/2020

Review began 04/29/2020

Review ended 06/05/2020

Published 06/15/2020

\section{() Copyright 2020}

Anderson et al. This is an open access article distributed under the terms of the Creative Commons Attribution License CC-BY 4.0., which permits unrestricted use, distribution, and reproduction in any medium, provided the original author and source are credited.

\section{Conclusions}

This study demonstrated that medical students were successfully able to conduct large-scale HOCPR training that improved CPR knowledge and comfort levels among participants across multiple metropolitan areas. Knowledge retention remained higher at two-years for participants of a follow-up questionnaire. Medical students can use the experiences from this training event as a template to organize similar largescale training events in the future.

Categories: Emergency Medicine, Medical Education, Epidemiology/Public Health

Keywords: cardiopulmonary resuscitation, education, medical students, community participation

\section{Introduction}

Cardiac arrest is one of the leading causes of death among adults over the age of 40 ; hence, even small incremental improvements in survival can translate into thousands of lives saved each year [1-3]. Bystander cardiopulmonary resuscitation (CPR) is a key factor in the Chain of Survival. Although at least half of out-ofhospital cardiac arrests (OHCA) are witnessed and bystander-initiated CPR can substantially increase the likelihood of survival, the rate of bystander CPR remains low in most countries [1, 3, 4-8]. In recent years, there has been an increased effort to teach bystanders hands-only CPR (HOCPR) since it has similar survival rates as conventional $\mathrm{CPR}$, is easier to teach, remember, and perform, and was designed to overcome potential barriers to bystander performance of CPR, such as panic and reluctance to perform mouth-tomouth ventilations [9-10]. 
HOCPR training has been implemented through traditional classroom programs. However, the rate of bystander CPR in many communities and demographic groups remains very low [11]. Numerous strategies have been implemented to reach a larger number of lay rescuers, including video self-instruction and media [12-13]. In one instance, a single large-scale training session was used to train over 5,000 bystanders about conventional CPR in Singapore, but the utility of large-scale training sessions using HOCPR has not yet been well-explored [14].

In this study, we aimed to create a single-day state-wide HOCPR training event that was organized and conducted by medical students. The goal of our study was to assess the feasibility of using a large-scale HOCPR training event, conducted by medical students, to increase participant CPR knowledge and their comfort level performing HOCPR. We also explored what effect this training event had on perceived barriers to bystander-performed CPR.

\section{Materials And Methods \\ Study design and setting}

The Texas Two-Step CPR training event was organized and conducted by medical students on a single day (February 6, 2016) at 53 public locations in 10 cities across the state of Texas (Figure 1). Public locations for the event included college campuses, museums, recreation centers, retail centers, healthcare clinics, religious centers, and a theater. The event Board of Directors (BOD) included six medical students who organized operations, communications, public relations, and media, as well as event registration and research. The BOD recruited medical student volunteers from each of the nine Texas medical schools and instituted a board of four students from each institution to direct 1) volunteers, 2) locations, 3) equipment, and 4) outreach at their respective institutions.

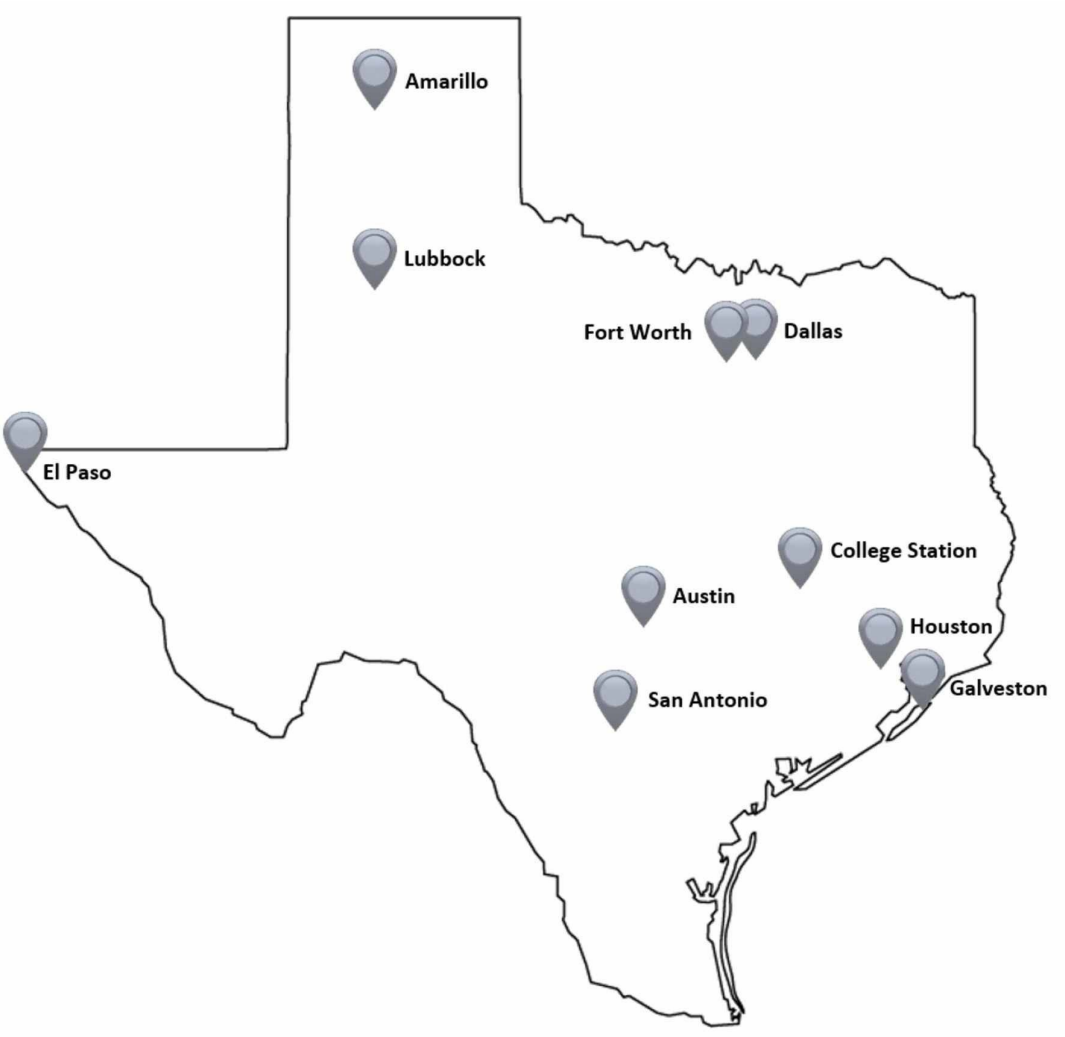

FIGURE 1: Training cities

To evaluate the effect of the event, a convenience sample of participants attending the first annual Texas Two-Step CPR training event completed a pre- and post-event questionnaire of CPR knowledge and comfort level. All adult participants (age $\geqslant 18$ years) were eligible for inclusion; the initial intent was to include all event participants, but several event site leaders decided not to distribute the questionnaires because doing so disrupted the flow of participants through the educational event. Participants were excluded if they were unable to complete the written questionnaire in English or had a physical disability that precluded them from participating in the training event. The study was approved by the Institutional Review Board with a waiver of documentation of informed consent; reporting follows the Strengthening the Reporting of Observational Studies in Epidemiology (STROBE) statement for observational studies [15]. 


\section{Intervention}

Following recruitment and informed consent, participants completed a pre-training registration form, including demographic information, prior CPR training, follow-up contact information, and CPR comfort level, as well as the HOCPR pre-test developed by the American Heart Association (AHA) (Appendix 1-2) [16]. Participants subsequently watched a five-minute scripted demonstration of HOCPR in either English or Spanish performed by student volunteers trained in HOCPR. Training also introduced the Good Samaritan Law to alleviate concerns regarding legal liability when performing CPR in public [17]. Participants were subsequently allowed a five to 10 minute assisted practice session with feedback from the medical student proctors until they were able to independently perform HOCPR correctly, including a simulated call to emergency medical services (911) and closed-chest compressions on mannequins at the appropriate rate and depth. After completion of the training, participants completed a post-event questionnaire, including CPR comfort level and the AHA-developed HOCPR post-test (Appendix 3) [16].

\section{Follow-up}

For participants who agreed to participate in the follow-up survey, a questionnaire with the same CPR comfort level questions and HOCPR post-test (Appendix 3) were sent to participants to be completed 23-24 months following the Texas Two-Step CPR training event [16]. The follow-up questionnaire included two additional questions asking whether participants had either shared or used the CPR knowledge they gained (Appendix 4).

\section{Outcomes}

The purpose of this study was to determine whether it was feasible for medical students to organize a largescale multi-community HOCPR training event. Similar to prior CPR training studies, to determine if this event might have any potential public health benefit, the primary outcomes of interest were the difference in CPR knowledge and comfort level between pre- and post-event surveys [18]. Demographic contributions to pre- and post-event knowledge and comfort level, as well as two-year follow-up knowledge and comfort level, were also assessed. Participant responses to open-ended questions are listed in Appendix 5.

\section{Analysis}

Paired sample t-tests and Wilcoxon rank sign tests were used, as appropriate, to compare pre-, post-, and follow-up tests. Additionally, we used descriptive statistics to examine the distribution of primary outcomes and variables around 95\% confidence intervals. Spearman's correlation was used to assess relationships between participant demographics and test performance. Analysis of variance and correlation using both parametric and non-parametric statistics were used as appropriate. Analyses were run using Stata 15.1/SE for Windows (StataCorp, LP College Station, TX).

\section{Results}

\section{Study participants}

Four thousand two hundred and fifty-three participants received HOCPR training during the single-day Texas Two-Step CPR training event. Nineteen of the 53 training locations distributed the pre- and post-test questionnaires so 1,636 questionnaires (38\% of all participants) were distributed (Figure 2). Of the completed questionnaires, an additional 220 had subject identifiers that could not be matched between the pre- and post-test; thus, 1,416 (87\%) of the pre-and post-tests were available for analysis. Nine hundred and ninety-eight (70\%) of the subjects that submitted matching questionnaires at the event expressed willingness to participate in a follow-up survey and 707 (49\%) provided usable electronic mail addresses for follow-up. One hundred and one (14\%) of the subjects that provided usable contact information submitted follow-up questionnaires. Demographics are listed in Table 1. The training-day and follow-up samples did not differ in terms of prior CPR training, pre-test, or post-test knowledge scores; however, compared with the training-day sample, the follow-up sample was more comfortable performing CPR $(p<0.001)$, was about five years older $(p=0.003)$, and had a higher level of education $(p=0.015)$. 


\section{Cureus}

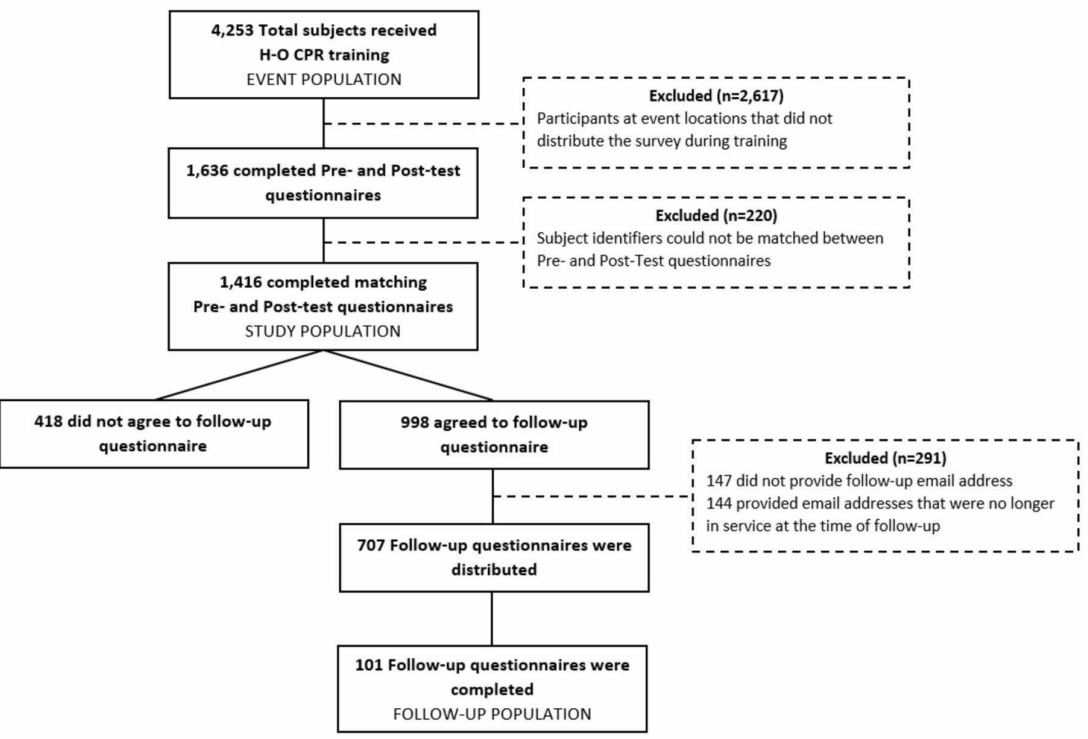

\section{FIGURE 2: Study population}

HOCPR: hands-only cardiopulmonary resuscitation

Variable

Age, years

Gender

Female

Male

Total

Ethnic background

White

Hispanic/Latino

Asian

Black/African American

Other/Mixed

Prefer not to answer

Total

Annual household income

$<\$ 25,000$

$\$ 25,000$ - \$49,999

\section{Training day}

$\mathrm{N}$

$1,445 \quad 24(19-38)$

$10130(20-47)$

Follow-up
Median (IQR) or \% (95\% Cl)

N Median (IQR) or \% $(95 \% \mathrm{Cl})$

$\begin{array}{ll}703 & 54(51-57) \\ 603 & 46(43-49)\end{array}$

60

$61(50-70)$

$3939(30-50)$

1,306

99

$\begin{array}{llll}508 & 39(36-41) & 48 & 48(38-58) \\ 414 & 32(29-34) & 24 & 24(16-34) \\ 162 & 12(11-14) & 10 & 10(4.9-18) \\ 117 & 9.0(7.4-11) & 11 & 11(5.6-19) \\ 52 & 3.9(3.0-5.1) & 2 & 2.0(0.2-7.0) \\ 63 & 4.8(3.7-6.1) & 5 & 5.0(1.6-11) \\ 1,316 & & 100 & \end{array}$

$169 \quad 13(12-15)$

$17 \quad 18(11-27)$

$178 \quad 14(12-16)$

$13 \quad 14(7.4-22)$ 


\section{Cureus}

\begin{tabular}{|c|c|c|c|c|}
\hline$\$ 50,000-\$ 74,999$ & 154 & $12(11-14)$ & 13 & $14(7.4-22)$ \\
\hline$\$ 75,000-\$ 99,999$ & 124 & $9.8(8.3-12)$ & 5 & $5.2(1.7-12)$ \\
\hline$\$ 100,000-\$ 149,999$ & 138 & $11(9.3-13)$ & 16 & $17(9.8-26)$ \\
\hline$\$ 150,000$ or more & 123 & $9.8(8.2-12)$ & 12 & $13(6.6-21)$ \\
\hline Prefer not to answer & 374 & $30(27-32)$ & 20 & $21(13-30)$ \\
\hline Total & 1,260 & & 96 & \\
\hline \multicolumn{5}{|l|}{ Highest education level } \\
\hline Did not complete any schooling & 35 & $2.8(2.0-3.9)$ & 0 & 0.0 \\
\hline Did not graduate from high school & 150 & $12(10-14)$ & 6 & $6.1(2.3-13)$ \\
\hline High school degree or equivalent (e.g., GED) & 168 & $13(12-15)$ & 11 & $11.1(5.7-19)$ \\
\hline Some college but no degree & 357 & $29(26-31)$ & 23 & $23(15-33)$ \\
\hline Associate or technical degree & 59 & $4.7(3.6-6.0)$ & 9 & $9.1(4.2-17)$ \\
\hline Bachelor's degree & 306 & $24(22-27)$ & 32 & $32(23-43)$ \\
\hline Master's degree & 116 & $9.3(7.7-11)$ & 12 & $12.1(6.4-20)$ \\
\hline Professional or Doctorate degree & 61 & $4.9(3.7-6.2)$ & 6 & $6.1(2.3-13)$ \\
\hline Total & 1,252 & & 99 & \\
\hline \multicolumn{5}{|l|}{ Previous CPR Training } \\
\hline Yes & 568 & $46(43-48)$ & 47 & $50(40-61)$ \\
\hline No & 681 & $55(52-57)$ & 47 & $50(40-61)$ \\
\hline Total & 1,249 & & 94 & \\
\hline \multicolumn{5}{|l|}{ Reasons to learn CPR } \\
\hline To learn how to help someone in need & 1016 & $62(60-64)$ & 87 & $67(59-75)$ \\
\hline Work requirement & 184 & $11(9.7-13)$ & 10 & $7.7(3.1-12)$ \\
\hline None of the above & 64 & $4.0(2.8-4.9)$ & 1 & $0.8(0.7-2.3)$ \\
\hline Personally know someone with heart disease & 133 & $8.1(6.8-9.5)$ & 14 & $11(5.4-16)$ \\
\hline To teach others CPR & 152 & $9.3(7.9-11)$ & 13 & $10(4.8-15)$ \\
\hline Other* & 87 & $5.3(4.2-6.4)$ & 5 & $3.8(0.5-7.2)$ \\
\hline Total & 1,636 & & 130 & \\
\hline
\end{tabular}

\section{TABLE 1: Demographic Background of Respondents}

*See Appendix 5 for responses to 'Other.' Totals vary due to non-responses.

CI: confidence interval; CPR: cardiopulmonary resuscitation; GED: general educational development; IQR: interquartile range; N: number

\section{CPR knowledge}

Mean CPR knowledge scores improved between pre-and post-tests on the day of the training event (Table 2). Although the mean follow-up test scores decreased from the post-test scores, the follow-up scores remained higher than the pre-test scores. 


\section{Cureus}

\begin{tabular}{|c|c|c|c|}
\hline Survey & $\mathbf{N}$ & Mean \pm SD & p-value \\
\hline Training Pre-test & 1,414 & $2.7 \pm 1.6$ & $<0.001$ \\
\hline Training Post-test & 1,414 & $4.7 \pm 0.76$ & \\
\hline Training Post-test & 100 & $4.8 \pm 0.47$ & $<0.001$ \\
\hline Follow-up & 100 & $3.8 \pm 1.1$ & \\
\hline Training Pre-test & 98 & $2.9 \pm 1.4$ & $<0.001$ \\
\hline Follow-up & 98 & $3.8 \pm 1.1$ & \\
\hline
\end{tabular}

\section{TABLE 2: Mean Pre-Test, Post-Test, and Follow-up Test Scores for Five CPR Knowledge}

\section{Questions}

CPR: cardiopulmonary resuscitation; N: number; SD: standard deviation

Higher education levels correlated significantly with higher pre- $(r=0.266, \mathrm{p}<0.001)$ and post-test $(\mathrm{r}=$ $0.147, \mathrm{p}<0.001)$ scores, but not follow-up test scores $(\mathrm{r}=0.0384, \mathrm{p}=0.707)$. Those whose highest level of education was a bachelor's degree performed best on both pre- and post-tests $(3.3 \pm 1.4$ and $4.8 \pm 0.4$, respectively), while those who did not complete any schooling performed the worst on both pre- and posttests ( $1.5 \pm 1.5$ and $4.4 \pm 1.2$, respectively). During the follow-up, those whose highest level of education was an associate or technical degree performed the best on the test $(4.1 \pm 0.6)$, while those whose highest level of education was a high school degree or equivalent performed the worst $(3.4 \pm 1.6)$.

Similarly, there was a significant correlation between higher family incomes and higher pre- $(r=0.267, \mathrm{p}<$ 0.001 ) and post-test scores $(r=0.170, p=<0.001)$, but this correlation was not significant in follow-up scores $(r=0.002, p=0.986)$. It was found that those who had a family income of $<\$ 25,000$ performed worst on both pre- $(2.0 \pm 1.7)$ and post-tests $(4.5 \pm 0.9)$, but those who had an income of $\geqslant \$ 150,000$ performed the best on both tests (pre: $3.3 \pm 1.1$, post: $4.8 \pm 0.5$ ). On the follow-up test, those whose family income was 75,000 - 99,999 performed best on average $(4.8 \pm 0.5)$ while those who made $25,000-49,999$ performed worst on average $(3.5 \pm 1.1)$.

There was also a significant difference between ethnic background and pre- and post-test scores $(\mathrm{p}<0.001)$ with White/Caucasian participants receiving the highest scores on average (pre: $3.2 \pm 1.3$, post: $4.8 \pm 0.5$ ) and Other/Mixed receiving the lowest scores on average (pre: $2.0 \pm 1.7$, post: $4.4 \pm 1.2$ ). There was not a significant relationship between ethnic background and follow-up scores $(\mathrm{p}=0.948)$ with Other/Mixed performing the best on average $(4.0 \pm 1.4)$ and Hispanic/Latino performing the worst on average (3.6 \pm 1.3$)$.

\section{CPR comfort level}

Reported CPR comfort level improved between pre- and post-event questionnaires $(\mathrm{p}<0.001)$ (Table 3). Although there was a trend toward decreased comfort levels between the post-test and the follow-up ( $\mathrm{p}=$ $0.220)$, follow-up comfort remained higher than pre-test comfort $(p=0.029)$. 


\section{Cureus}

\begin{tabular}{|c|c|c|c|}
\hline \multirow[t]{2}{*}{ Question } & Pre-Test & Post-Test & Follow-Up \\
\hline & $\%(95 \% \mathrm{Cl})$ & $\%(95 \% \mathrm{Cl})$ & $\%(95 \% \mathrm{Cl})$ \\
\hline \multicolumn{4}{|c|}{$\begin{array}{l}\text { Would you feel comfortable performing Hands-Only CPR if someone had a cardiac } \\
\text { arrest? }\end{array}$} \\
\hline Yes & $59(56-61)$ & $96(95-97)$ & $78(69-86)$ \\
\hline No & $41(39-44)$ & $\begin{array}{l}4.1(3.1- \\
5.2)\end{array}$ & $22(14-31)$ \\
\hline \multicolumn{4}{|c|}{$\begin{array}{l}\text { If you would NOT feel comfortable performing Hands-Only CPR now, please explain } \\
\text { why: }\end{array}$} \\
\hline I don't feel I know how to correctly perform CPR & $59(55-62)$ & $19(15-24)$ & $31(15-51)$ \\
\hline I may be legally liable if I get involved & $\begin{array}{l}6.6(5.0- \\
8.6)\end{array}$ & $18(14-23)$ & $31(15-51)$ \\
\hline I may hurt someone or do CPR wrong if I get involved & $19(16-22)$ & $34(29-40)$ & $14(3.9-32)$ \\
\hline I am afraid of getting a disease & $\begin{array}{l}2.3(1.4- \\
3.6)\end{array}$ & $\begin{array}{l}2.2(0.8- \\
4.7)\end{array}$ & $2.9(1.0-8.3)$ \\
\hline Other* & $14(11-16)$ & $27(22-33)$ & $0.0(0.0-3.6)$ \\
\hline \multicolumn{4}{|c|}{ Would you recommend this CPR training to a friend of a family member? } \\
\hline Yes & - & $99(99-100)$ & $99(95-100)$ \\
\hline No & - & $\begin{array}{l}0.7(0.3- \\
1.4)\end{array}$ & $1.0(0.0-5.5)$ \\
\hline \multicolumn{4}{|c|}{ Have you told anyone about what you learned in your CPR training? } \\
\hline Yes & - & - & $53(42-63)$ \\
\hline No & - & - & $47(37-58)$ \\
\hline \multicolumn{4}{|c|}{ Have you used what you learned about CPR since the training in February $2016 ?$} \\
\hline Yes & - & - & $4.0(1.1-10)$ \\
\hline No & - & - & $96(90$ - 99) \\
\hline
\end{tabular}

\section{TABLE 3: Responses to Pre-Test, Post-Test, and Follow-up Questions About the CPR Training}

*See Appendix 5 for responses to 'Other'

Cl: confidence interval; CPR: cardiopulmonary resuscitation

Education contributed significantly to comfort at both pre- $(p=0.015)$ and post-training $(p=0.026)$ but not for follow-ups ( $\mathrm{p}$ 0.062). Comfort did not differ significantly by family income nor ethnicity in any of the tests. On average, those who felt comfortable during the pre-test scored 0.7 higher (95\% CI: $0.5-0.9$, p-value $<0.001)$ than those who felt uncomfortable. During the post-test, those who felt comfortable scored, on average, 0.9 higher $(95 \%$ CI: $0.7-1.1$, p-value < 0.001). Similarly, during the follow-up test, those who felt comfortable scored 0.6 higher on average $(95 \% \mathrm{CI}$ : $0.2-1.2$, p-value $=0.010)$.

\section{Perceived barriers}

The most common pre-training reason for not being comfortable with CPR was not knowing how to correctly perform CPR (Table 3). Post-training, the most common reason was a concern for hurting someone. However, during follow-up, the most common reason was a tie between not knowing how to correctly perform CPR and being legally liable if they got involved.

\section{Discussion}

In our study, we found that medical students were able to successfully organize and conduct a large-scale HOCPR training event with improvement in participant CPR knowledge and comfort-level performing 
HOCPR. We report a 40\% increase in CPR knowledge based on the AHA HOCPR pre- and post-tests, as well as a $37 \%$ increase in the number of participants that felt comfortable performing HOCPR after the single-day training event. Although the follow-up response rate was low, CPR knowledge and comfort were retained somewhat even two years later.

The Texas Two-Step CPR training event represents a new method of educating bystanders that does not require any prior CPR instructor experience. Although the organizers of this event were medical students with some experience with CPR, none had prior experience conducting CPR education sessions. Previous studies have demonstrated that school teachers with no prior CPR education experience were also able to conduct similar HOCPR training in a public-school setting [19]. Although HOCPR training methods vary substantially, "ideal CPR education sessions should be accessible for all people and result in increased knowledge and comfort among participants" [19-20]. In this regard, the Texas Two-Step event was tremendously successful. The ethnic background of our study population (Table 1) closely reflects the demographics of the state of Texas which suggests that the training was indeed accessible and used by a representative cross-section of the targeted population [21]. Subsequently, all participants experienced an increase in CPR knowledge and comfort. Due to the ability of this initial training event to teach such a large number of bystanders in such a short period of time, the Texas Two-Step CPR training event has become an annual program that has expanded to 10 states and has trained more than 18,500 participants in HOCPR since inception [22].

In this study, there was a high proportion of participants who expressed comfort performing CPR after the training. In the post-test survey, $96 \%$ of participants expressed comfort performing HOCPR; this is higher than previous HOCPR studies [19, 23]. The reason for this discrepancy is likely multifactorial. However, this study demonstrated that the education level contributed to the comfort level, suggesting that participants with lower education levels may benefit from an emphasis on the factors that contribute to discomfort. Fortunately, at least one of the participants was confident enough to use their CPR skills to perform chest compressions during a cardiac arrest case (Appendix 5).

Our study also demonstrated a relationship between higher education and income with higher pre- and post-test scores. Although we did not specifically look for a correlation between education and income levels, this relationship is well-known [24]. Higher pre-test scores suggest that participants with higher education or income either had preexisting CPR knowledge, were better test-takers, or both. Lower education and income have been associated with less exposure to CPR training which is likely the major contributing factor in this study [25]. The relationship between education and higher test scores did not hold true for the follow-up survey which suggests that the questions were sufficiently simple enough that the test-taking strategy had less of an influence, and the exposure to CPR concepts during this training event may have equalized the disparity due to education or income over the long-term. Further analysis would be required to verify this premise. Nonetheless, these findings are encouraging as they suggest that even brief exposure to CPR concepts may have longstanding benefits.

Although bystander CPR increases survival and improves health outcomes from cardiac arrest, less than onehalf of out-of-hospital cardiac arrest victims receive bystander CPR [1, 11, 26]. Only a few prior studies have focused on the potential barriers to bystander CPR [27-28]. However, our study echoes previous work suggesting that bystanders without CPR training are less willing to attempt CPR due to their lack of CPR knowledge or experience. After the training event, our study found that the most common perceived barrier became a concern for causing harm which is a barrier that has also been expressed in prior work [27-28]. In contrast to some previous studies, few of our participants were concerned about contracting a disease from victims; this is likely due to the nature of HOCPR which eliminates mouth-to-mouth contact [27-

28]. Although HOCPR overcomes some of the barriers to bystander CPR, further work needs to be done to overcome commonly reported barriers - some of which are simply misperceptions among the general public. Large-scale, no-cost training events, such as the one we held in this study, may be one way to rapidly increase CPR knowledge and experience among large numbers of bystanders. These training events could also be used as a platform to address some of the common misperceptions which continue to be barriers to bystander-performed CPR.

\section{Limitations}

Our study had some limitations. First, this was a convenience sample of participants during a single day training event and was subject to selection bias. Many of the training location leaders did not distribute the questionnaires because they thought it disrupted the flow of the training session. However, the demographics of our training day population reflect the demographics of the state of Texas which suggests that the training session was successful in reaching a representative subset of the target population (Table 1) [21]. This is encouraging since the African American and Hispanic ethnic groups traditionally do not learn CPR or perform bystander CPR at the rate of other ethnic groups [29-30]. Our study demonstrates that community outreach was able to successfully target these hard to reach groups as well. In fact, the HOCPR training was held in both English and Spanish at some of the sites. However, the questionnaire was not translated into Spanish, so our results may under-represent the Hispanic population who participated in the event. Nonetheless, participants of this training event self-selected rather than being randomly chosen; those who participated in the training may have been more likely to consider providing CPR at baseline. 
Additionally, there is the potential for a Hawthorne effect in the follow-up survey - participants may have looked up the answers if they wanted a higher score. Second, the results for the follow-up sample may not be representative of the original training-day sample. As mentioned in the results section, the two samples do not differ in terms of prior CPR training, pre-test, or post-test knowledge scores. However, compared with the original sample, the follow-up sample was more comfortable performing CPR, was older, and more educated. These differences may introduce potential selection bias, and the results should be considered accordingly. Lastly, the AHA CPR guidelines changed in October 2015, just a few months before the Texas Two-Step CPR training day. The online pre- and post-test changed in January after materials for the training day had been printed. The questions did not change, but the answer for the correct number of chest compressions in a one-minute period has changed from "at least 100" to "100 - 120." It is unlikely that this change made any difference since the answers are almost identical, except for the new upper limit of 120. Additionally, in the online follow-up, we were unable to test manual skills, including compression rate, depth, and lean. During the training event, all subjects demonstrated these manual skills, but the format of the follow-up did not allow the assessment of these skills.

\section{Conclusions}

In summary, medical students were able to successfully organize and conduct a large-scale hands-only CPR training event that improved participant CPR knowledge and comfort level. Although there was some decrease in both knowledge and comfort after the event, both remained higher than the pre-test baseline at a two-year follow-up. Our study also identified perceived barriers to bystander-performed CPR change with training and time after training. Medical students can use the experiences from this training event as a template to organize similar large-scale training events in the future.

\section{Appendices}

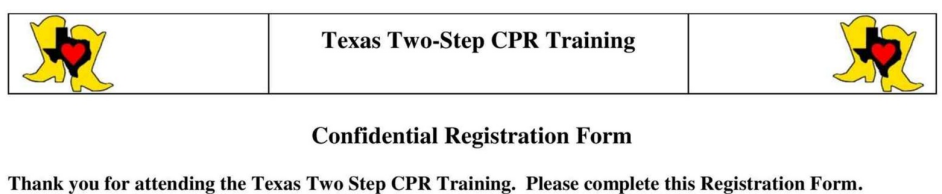

All information you provide will remain confidential. We will not share this information with anyone, and we will use it only for our records and to evaluation of this CPR training. PLEASE PRINT

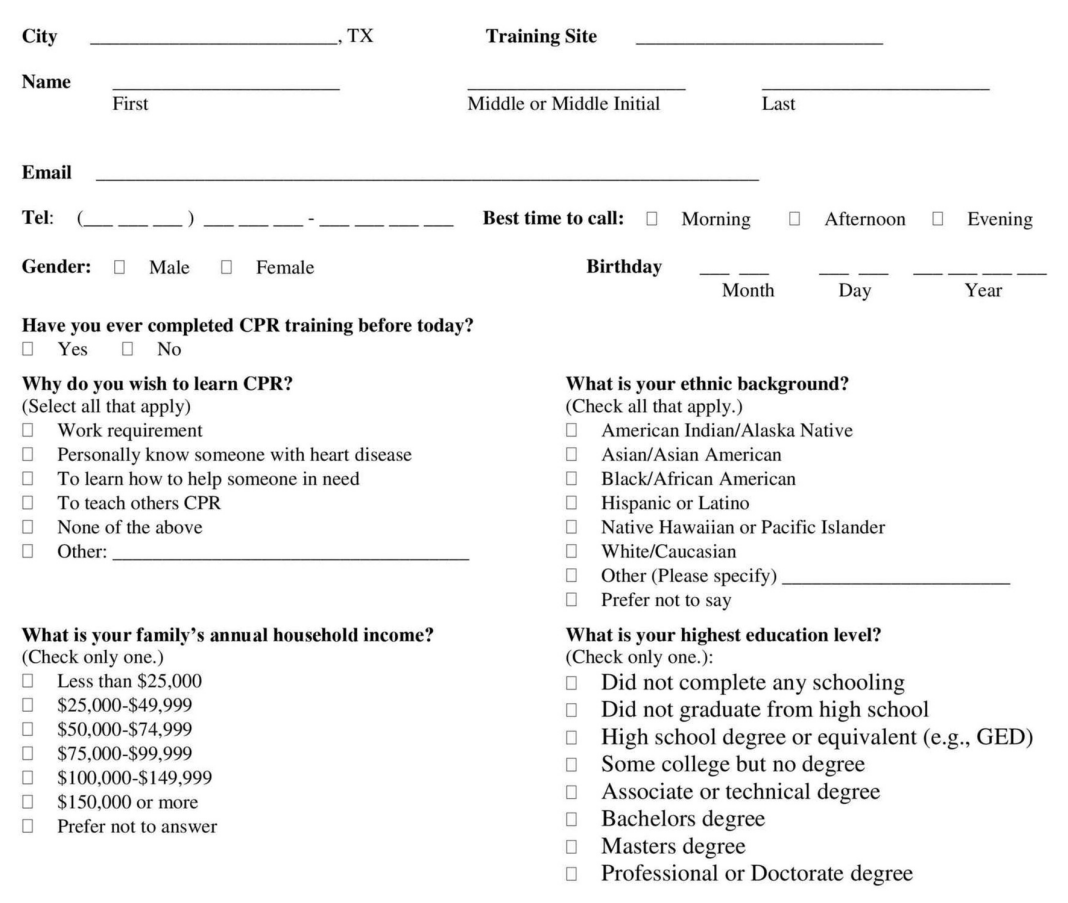

Follow-up Contact: In about 12 months, we would like to contact you by email or telephone to evaluate this CPR training, and we may ask you some other health related questions.

May we contact you in about 12 months? $\quad \square$ Yes $\square \quad$ No

FIGURE 3: Appendix 1: Registration form 


\section{Cureus}

\begin{tabular}{|c|c|}
\hline Texas Two-Step CPR Training \\
Pre-Test
\end{tabular}

City , TX

Training Site

Name $\overline{\text { Middle or Middle Initial }} \quad \overline{\text { Last }}$

Please check the ONE BEST answer for each question.

1. When performing Hands-Only CPR, how many times should you push in the center of the chest during a one minute period?

$\square$ At least 50

At least 150

At least 100

I don't know

2. When do you stop pushing on the victim's chest during Hands-Only CPR?

$\square 5$ minutes

When I get too tired

When medical professionals take over

I don't know

4. What does an Automated External Defibrillator (AED) do?

\. Shocks the heart and restarts the heart to a normal rhythm

Automatically dials 911 and calls for help

$\square$ Performs CPR, dials 911 and restarts the heart

I I don't know

5. What are the correct steps for providing HandsOnly CPR?

( Dial 911, push hard and fast in the center of the chest, and get an AED

Push hard and fast in the center of the chest then dial 911 and get an AED

- Give two breaths then dial 911

I I don't know

3. How deep should you push on the chest of an adult 6. Would you feel comfortable performing Handswhen doing Hands-Only CPR?
1 inch
2 inches
$\square$ Yes
3 inches

the perfiac arrest?

Idon't know

7. If you would NOT feel comfortable performing Hands-Only CPR now, please explain why

I don't feel I know how to correctly perform CPR

I may be legally liable if I get involved

I may hurt someone or do CPR wrong if I get involved

I am afraid of getting a disease

Other (Please explain):

Please turn in your completed Registration and Pre-Test with your Post-Test after you complete your training.

FIGURE 4: Appendix 2: Pre-test 


\section{Cureus}

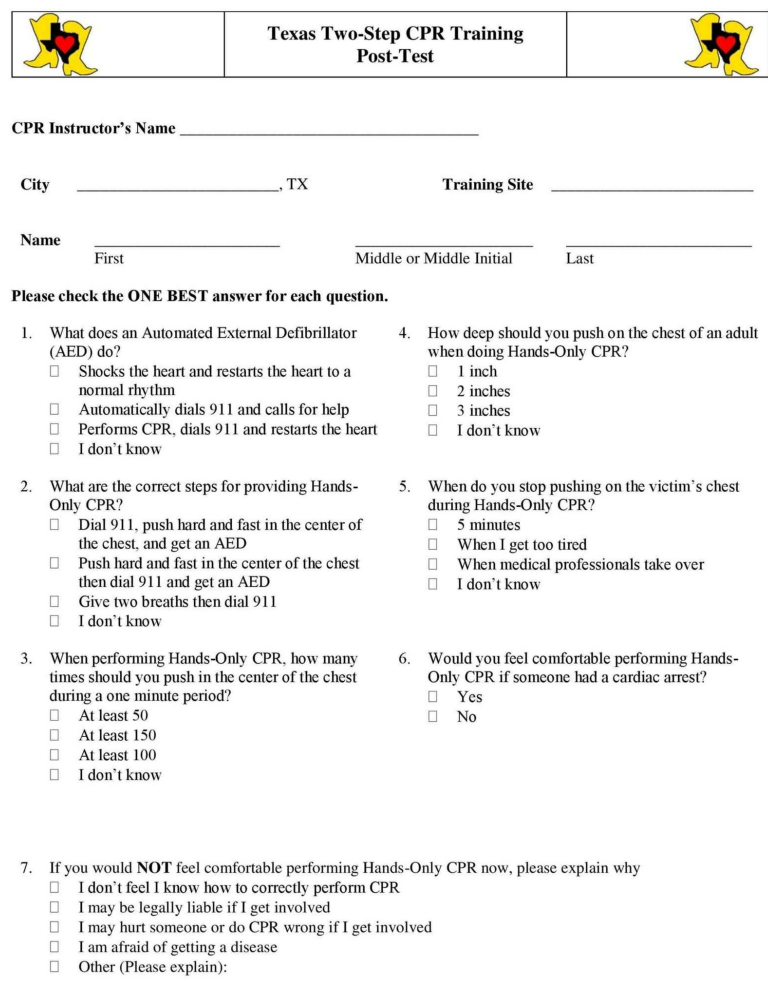

Please continue on the reverse side of this page. $\longrightarrow$

\begin{tabular}{|l|c|}
\hline & $\begin{array}{c}\text { Texas Two-Step CPR Training } \\
\text { Post-Test }\end{array}$ \\
\hline
\end{tabular}

\footnotetext{
9. Would you recommend this CPR training to a friend or family member? Yes $\square$ No

10. Please tell us what you liked most about the CPR training? What helped you the most?
}

11. Please tell us what could have been done better so we can improve the next CPR training.

Thank you. Please turn in your completed Registration, Pre-Test, and Post-Test before you leave.

FIGURE 5: Appendix 3: Post-test 


\section{Cureus}

\begin{tabular}{|l|l|l|}
\hline & Texas Two-Step CPR Training \\
\hline
\end{tabular}

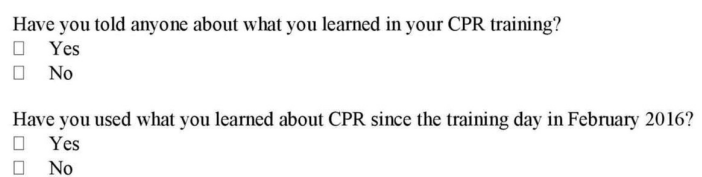

FIGURE 6: Appendix 4: Follow-up confidence questions 


\section{Cureus}

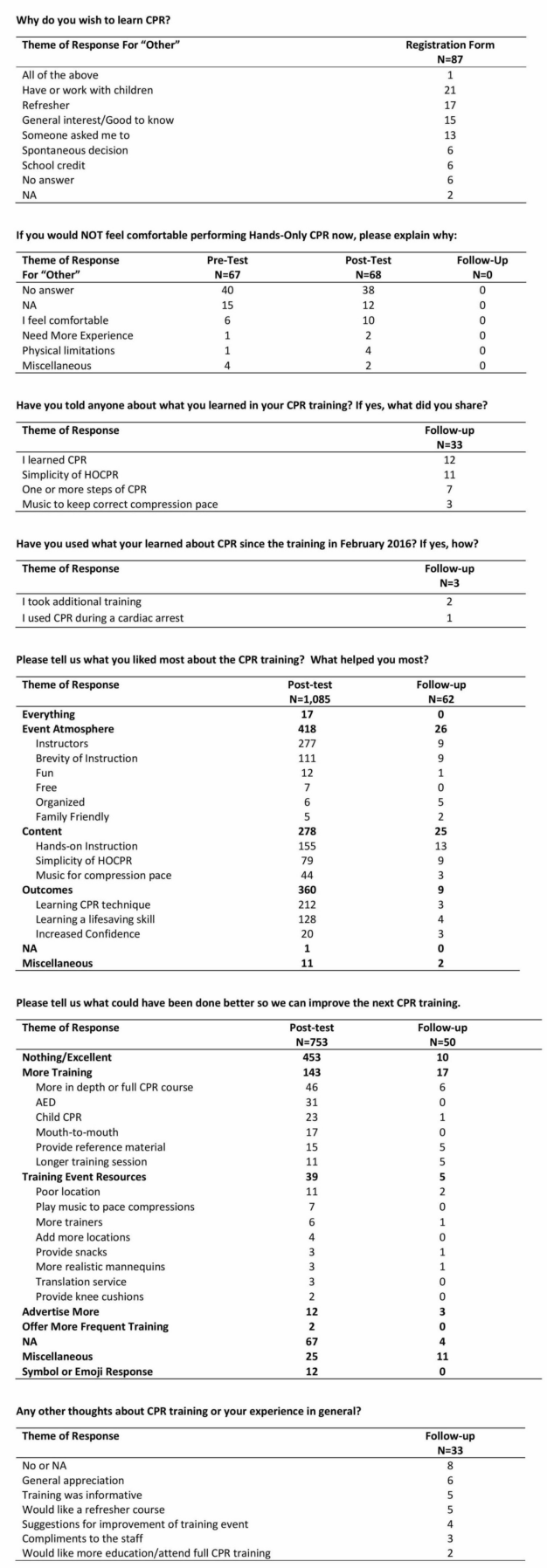

FIGURE 7: Appendix 5: Tables for open-ended questions

\section{Additional Information \\ Disclosures}

Human subjects: Consent was obtained by all participants in this study. Baylor College of Medicine issued approval ESP1:H-38424. The title of the protocol is: The Educational Feasibility of a Large-Scale HandsOnly CPR Training Program . Animal subjects: All authors have confirmed that this study did not involve animal subjects or tissue. Conflicts of interest: In compliance with the ICMJE uniform disclosure form, all authors declare the following: Payment/services info: All authors have declared that no financial support was received from any organization for the submitted work. Financial relationships: All authors have declared that they have no financial relationships at present or within the previous three years with any organizations that might have an interest in the submitted work. Other relationships: All authors have declared that there are no other relationships or activities that could appear to have influenced the 
submitted work.

\section{Acknowledgements}

The following project sponsors provided funding for the training event: American College of Emergency Physicians, HealthCorps, MaveRx, Texas College of Emergency Physicians, and Texas Medical Association. We would also like to acknowledge the organization, leadership, and service provided by more than 650 medical students from all nine Texas medical schools. Of note, the following core team of medical students directed the operations of the project: Nick Salerno (Co-chair of Operations, University of Texas Health Sciences Center San Antonio), Faroukh Mehkri (Co-chair of Operations, University of North Texas Health Science Center), Kayla Olesky (Director of Communications, University of North Texas Health Science Center), Jake Valentine (Director of Operations, Baylor College of Medicine), Shehni Nadeem (Director of Media and Public Relations, Baylor College of Medicine), Mackenzie Hicks (Director of Registration and Research, Baylor College of Medicine). Angela Fisher, M.D. (MaveRx) also provided operational mentorship for the medical students.

\section{References}

1. Benjamin EJ, Virani SS, Callaway CW, et al.: Heart disease and stroke statistics--2018 update: a report from the American Heart Association. Circulation. 2018, 137 :e67-e492. 10.1161/CIR.0000000000000558

2. Dunne RB, Compton S, Zalenski RJ, Swor R, Welch R, Bock BF: Outcomes from out-of-hospital cardiac arrest in Detroit. Resuscitation. 2007, 72:59-65. 10.1016/j.resuscitation.2006.04.017

3. Sasson C, Rogers MA, Dahl J, Kellermann AL: Predictors of survival from out-of-hospital cardiac arrest: a systematic review and meta-analysis. Circ Cardiovasc Qual Outcomes. 2010, 3:63-81. 10.1161/CIRCOUTCOMES.109.889576

4. Sayre MR, Berg RA, Cave DM, Page RL, Potts J, White RD, American Heart Association Emergency Cardiovascular Care Committee: Hands-only (compression-only) cardiopulmonary resuscitation: a call to action for bystander response to adults who experience out-of-hospital sudden cardiac arrest: a science advisory for the public from the American Heart Association Emergency Cardiovascular Care Committee. Circulation. 2008, 117:2162-67. 10.1161/CIRCULATIONAHA.107.189380

5. Ong ME, Ng FS, Anushia P, et al.: Comparison of chest compression only and standard cardiopulmonary resuscitation for out-of-hospital cardiac arrest in Singapore. Resuscitation. 2008, 78:119-26. 10.1016/.resuscitation.2008.03.012

6. Dumas F, Rea TD, Fahrenbruch C, et al.: Chest compression alone cardiopulmonary resuscitation is associated with better long-term survival compared with standard cardiopulmonary resuscitation. Circulation. 2013, 127:435-41. 10.1161/CIRCULATIONAHA.112.124115

7. Vaillancourt C, Grimshaw J, Brehaut JC, Osmond M, Charette ML, Wells GA, Stiell IG: A survey of attitudes and factors associated with successful cardiopulmonary resuscitation (CPR) knowledge transfer in an older population most likely to witness cardiac arrest: design and methodology. BMC Emerg Med. 2008, 8:13. 10.1186/1471-227X-8-13

8. Lerner EB, Sayre MR, Brice JH, White LJ, Santin AJ, Billittier AJ 4th, Cloud SD: Cardiac arrest patients rarely receive chest compressions before ambulance arrival despite the availability of pre-arrival CPR instructions. Resuscitation. 2008, 77:51-56. 10.1016/j.resuscitation.2007.10.020

9. Hew P, Brenner B, Kaufman J: Reluctance of paramedics and emergency medical technicians to perform mouth-to-mouth resuscitation. J Emerg Med. 1997, 15:279-84. 10.1016/s0736-4679(97)00006-1

10. Swor R, Khan I, Domeier R, Honeycutt L, Chu K, Compton S: CPR training and CPR performance: do CPRtrained bystanders perform CPR?. Acad Emerg Med. 2006, 13:596-601. 10.1197/j.aem.2005.12.021

11. Rea TD, Cook AJ, Stiell IG, et al.: Predicting survival after out-of-hospital cardiac arrest: role of the Utstein data elements. Ann Emerg Med. 2010, 55:249-57. 10.1016/j.annemergmed.2009.09.018

12. Einspruch EL, Lynch B, Aufderheide TP, Nichol G, Becker L: Retention of CPR skills learned in a traditional AHA Heartsaver course versus 30-min video self-training: a controlled randomized study. Resuscitation. 2007, 74:476-86. 10.1016/j.resuscitation.2007.01.030

13. Bobrow BJ, Vadeboncoeur TF, Spaite DW, et al.: The effectiveness of ultrabrief and brief educational videos for training lay responders in hands-only cardiopulmonary resuscitation: implications for the future of citizen cardiopulmonary resuscitation training. Circ Cardiovasc Qual Outcomes. 2011, 4:220-26. 10.1161/CIRCOUTCOMES.110.959353

14. Fong YT, Anantharaman V, Lim SH, Leong KF, Pokkan G: Mass cardiopulmonary resuscitation 99 survey results of a multi-organisational effort in public education in cardiopulmonary resuscitation. Resuscitation. 2001, 49:201-205. 10.1016/s0300-9572(01)00312-4

15. von Elm E, Altman DG, Egger M, Pocock SJ, Gøtzsche PC, Vandenbroucke JP for the STROBE Initiative: The Strengthening the Reporting of Observational Studies in Epidemiology (STROBE) Statement: guidelines for reporting observational studies. Lancet. 2007, 370:1453-57. 10.1016/S0140-6736(07)61602-X

16. Hands-only CPR training PRE-TEST and POST-TEST . (2016). Accessed: January 30, 2016: http://www.heart.org/idc/groups/heart-public/@wcm/@ecc/documents/downloadable/ucm 468797.pdf.

17. Texas.gov. (2020). Accessed: June 10, 2020: http://statutes.capitol.texas.gov/Docs/CP/htm/CP.74.htm.

18. Kitamura T, Nishiyama C, Murakami Y, et al.: Compression-only CPR training in elementary schools and student attitude toward CPR. Pediatr Int. 2016, 58:698-704. 10.1111/ped.12881

19. Magid KH, Heard D, Sasson C: Addressing gaps in cardiopulmonary resuscitation education: training middle school students in hands-only cardiopulmonary resuscitation. J Sch Health. 2018, 88:524-30. 10.1111/josh.12634

20. Sasson C, Meischke H, Abella BS, et al.: American Heart Association Council on Quality of Care and Outcomes Research, Emergency Cardiovascular Care Committee, Council on Cardiopulmonary, Critical Care, Perioperative and Resuscitation, Council on Clinical Cardiology, and Council on Cardiovascular Surgery and 


\section{Cureus}

Anesthesia. Increasing cardiopulmonary resuscitation provision in communities with low bystander cardiopulmonary resuscitation rates: a science advisory from the American Heart Association for healthcare providers, policymakers, public health departments, and community leaders. Circulation. 2013, 127:134250.10.1161/CIR.0b013e318288b4dd

21. Quick Facts, Texas. (2019). Accessed: October 10, 2019:

http://www.census.gov/quickfacts/fact/table/tx/PST045217.

22. National Two Step CPR. (2020). Accessed: April 1, 2020: http://www.twostepcpr.com/.

23. Blewer AL, Leary M, Esposito EC, Gonzalez M, Riegel B, Bobrow B, Abella B: Continuous chest compression cardiopulmonary resuscitation training promotes rescuer self-confidence and increased secondary training: a hospital-based randomized controlled trial. Crit Care Med. 2012, 40:787-92.

10.1097/CCM.0b013e318236f2ca

24. Data on Display: Education Matters . (2016). Accessed: October 10, 2019: http://www.bls.gov/careeroutlook/2016/data-on-display/education-matters.htm.

25. Blewer AL, Ibrahim SA, Leary M, et al.: Cardiopulmonary resuscitation training disparities in the United States. J Am Heart Assoc. 2017, 6:e006124. 10.1161/JAHA.117.006124

26. Bagai A, McNally BF, Al-Khatib SM, et al.: Temporal differences in out-of-hospital cardiac arrest incidence and survival. Circulation. 2013, 128:2595-602. 10.1161/CIRCULATIONAHA.113.004164

27. Becker TK, Gul SS, Cohen SA, et al.: Public perception towards bystander cardiopulmonary resuscitation . Emerg Med J. 2019, 36:660-65. 10.1136/emermed-2018-208234

28. Cho GC, Sohn YD, Kang KH, et al.: The effect of basic life support education on laypersons' willingness in performing bystander hands only cardiopulmonary resuscitation. Resuscitation. 2010, 81:691-94. 10.1016/j.resuscitation.2010.02.021

29. Sasson C, Magid DJ, Chan P, et al.: Association of neighborhood characteristics with bystander-initiated CPR. N Engl J Med. 2012, 367:1607-15. 10.1056/NEJMoa1110700

30. Moon S, Bobrow BJ, Vadeboncoeur TF, et al.: Disparities in bystander CPR provision and survival from outof-hospital cardiac arrest according to neighborhood ethnicity. Am J Emerg Med. 2014, 32:1041-45. 10.1016/j.ajem.2014.06.019 